\title{
TEMPERATURA E DISPONIBILIDADE DE OXIGÊNIO NO CRESCIMENTO DE PLÂNTULAS DE ARROZ IRRIGADO ${ }^{1}$
}

\author{
ANGÉLICA POLENZ WIELEWICKI², ANTONIO CARLOS S. ALBUQUERQUE BARROS ${ }^{3}$
}

\begin{abstract}
RESUMO - Embora o Rio Grande do Sul seja responsável por cerca de $40 \%$ da produção brasileira de arroz, a lavoura arrozeira gaúcha tem atravessado uma crise que está relacionada, entre outros fatores, com baixa competitividade, alto custo de produção e produtividade média abaixo do potencial genético dos genótipos utilizados. Uma das formas que se tem adotado para produzir respostas mais efetivas a essa crise reside na utilização do sistema pré-germinado, buscando diminuir custos de produção e aumentar a produtividade e, em função disso, ampliar a competitividade. Tendo em vista essas considerações, o presente trabalho tem como objetivos comparar o desenvolvimento inicial de plântulas de arroz de genótipos utilizados no RS (BR IRGA 409, BR IRGA 410, IRGA 416 e IRGA 417) sob diferentes temperaturas $\left(20,25\right.$ e $\left.30^{\circ} \mathrm{C}\right)$ e avaliar o crescimento inicial das plântulas em condições de aerobiose e anaerobiose. Nos tratamentos de anaerobiose as sementes ficaram 24 horas submersas, 24 horas em aerobiose e retornaram para a anaerobiose até o 14어. dia. Os resultados dos testes permitem concluir que: a) o genótipo BR IRGA 409 mostrou-se menos adaptado à semeadura em anaerobiose, quando em temperatura de $20^{\circ} \mathrm{C}$; b) em anaerobiose, os genótipos apresentaram crescimento radicular maior em temperaturas mais altas.
\end{abstract}

Palavras-chave: Oryza sativa, pré-germinado, crescimento de plântulas.

\section{TEMPERATURE AND AVAILABILITY OF OXYGEN IN FLOODED RICE SEEDLING GROWTH}

\begin{abstract}
Although the southern state of Rio Grande do Sul (RS) is responsible for about $40 \%$ of the Brazilian rice yield, its rice growing sector has been facing a crisis which is related, among other factors, to a profile of low competitiveness, high production costs and an average yield which is below the genetic potential of the varieties used. One of the ways which has been used to produce more effective responses to such crises lies in the use of a pre-germinated system, as a way of lowering production costs alongside with increasing productivity and thus enhancing competitiveness. Bearing such considerations in mind, this paper aims at comparing the initial development of rice seedlings of genotypes grown in RS (BR IRGA 409, BR IRGA 410, IRGA 416 e IRGA 417) at different temperatures $\left(20,25 \mathrm{e} 30^{\circ} \mathrm{C}\right)$ and evaluating the initial growth of seedlings under aerobic and anaerobic conditions. In the anaerobiosis treatments, the seeds were submerged for 24 hours, then were kept in aerobiosis for 24 hours and were finally kept in anaerobiosis for fourteen days. The results of the tests allowed the conclusion that: a) The BR IRGA 409 genotype is better adapted to early sowing in the anaerobiosis condition when the temperature is $20^{\circ} \mathrm{C}$; b) In anaerobiosis, the genotypes showed a more prominent radicular growth at higher temperatures.

Index terms: Oryza sativa, pre-germinated, seedling growth.
\end{abstract}

\footnotetext{
${ }^{1}$ Aceito para publicação em 03.12.2002; parte da Tese de Doutorado do primeiro autor.

2 Dra., Pesquisadora da Fundação Estadual de Pesquisa Agropecuária do Rio Grande do Sul - FEPAGRO; bolsista do CNPq; e-mail: fepagros@datanews-rs.com.br

${ }^{3}$ Prof., Dr. do Depto. de Fitotecnia da FAEM/UFPEL; e-mail: acbarros@ufpel.tche.br
}

\section{INTRODUÇÃO}

A lavoura de arroz no Rio Grande do Sul tem importância fundamental no cenário agroeconômico do estado, respondendo por $29 \%$ da safra de grãos do RS e por cerca de $43 \%$ do volume total de arroz produzido no Brasil (IRGA, 
2000). No entanto, a cultura passa por uma crise relacionada, dentre outros fatores, com a baixa competitividade em função de altos custos de produção e a ocorrência de arroz daninho, especialmente quando o sistema convencional de cultivo é utilizado. Neste sentido, tem-se buscado produzir alternativas que possibilitem uma melhor utilização do potencial genético dos genótipos e a diminuição dos custos de produção. Uma das alternativas que tem se destacado é a utilização do sistema pré-germinado, que já está implantado em aproximadamente $10 \%$ da área de produção de arroz no RS, representando cerca de 90 mil ha.

A maioria dos genótipos e linhagens promissoras obtidas no Rio Grande do Sul até o momento foi desenvolvida para o sistema convencional. Com o aumento da área cultivada no sistema pré-germinado e com a indisponibilidade de materiais específicos, evidencia-se a necessidade de avaliar os materiais disponíveis para esse sistema. Em função das peculiaridades do sistema pré-germinado, outros critérios, tais como resistência ao acamamento, vigor inicial e crescimento de plântulas em anaerobiose, devem ser considerados.

Em função da semeadura ocorrer em solo alagado, numa condição denominada de "semeadura anaeróbica" (Yamauchi et al., 1993), a capacidade das plantas emergirem da água e entrarem em contato com o oxigênio é determinante para o bom estabelecimento do sistema, evidenciando a necessidade de se enfocar, mais especificamente, o vigor inicial e o crescimento de plântulas em anaerobiose, levando em consideração diferentes genótipos utilizados na lavoura orizícola do Rio Grande do Sul.

Nesse sentido, Chapman \& Peterson (1962) afirmaram que a germinação de sementes e o subseqüente crescimento de plântulas de arroz, não parecem ser limitados pelo suprimento de oxigênio quando semeados em solos alagados, em função de que há oxigênio dissolvido na água, apesar dessa quantidade de oxigênio ser pequena (Ponnamperuma, 1972), se comparada à quantidade disponível num ambiente aeróbio.

No caso de sementes pré-germinadas, essas são semeadas diretamente sobre o solo alagado ou simplesmente saturado. Porém, a sobrevivência e o estabelecimento das plântulas varia de acordo com um complexo de fatores bióticos e abióticos (Yamauchi \& Winn, 1996), entre os quais se pode citar a temperatura da água, a disponibilidade de oxigênio e a capacidade de degradação e de síntese de biomoléculas de cada genótipo.

Em trabalho desenvolvido por Yamahuchi et al. (1993), foi observado que quando sementes pré-germinadas são distribuídas na superfície do solo alagado, genótipos com bom estabelecimento de plântulas tem elevadas taxas de emergência, de crescimento de plântulas, de massa seca e de porcentagem de estabelecimento. Constataram também diferença varietal significativa no estabelecimento de plântulas. Tal estabelecimento, no entanto, foi responsivo às condições ambientais e vigor de sementes. Os autores afirmam ainda que fatores genéticos estão envolvidos no sucesso do estabelecimento de plântulas em anaerobiose. Em função disso, concluíram que o estabelecimento das plântulas em solo submerso pode ser controlado pela interação entre fatores ambientais e de manejo (propriedades físicas, químicas e biológicas do solo, temperatura da água e profundidade da lâmina de água), características fisiológicas da planta (tolerância à submersão e a anaerobiose, habilidade na elongação do coleóptilo) e vigor da semente.

Comparando genótipos utilizados na região sul do Brasil, Petrini at al. (1997), observaram que os genótipos EMBRAPA 7-TAIM, EMBRAPA 6-CHUÍ, IRGA 416 e BR IRGA 410 apresentaram melhor adaptação ao sistema prégerminado, tomando por base o desenvolvimento inicial verificado e a produtividade obtida. Porém, as razões para esses comportamentos não foram avaliadas.

De forma semelhante, Rosso et al. (1999) compararam vigor inicial de genótipos de arroz no sistema pré-germinado em dois municípios do RS e observaram que, em Cachoeirinha (RS), uma linhagem (IRGA 284-18-2-2-2) e os genótipos BR IRGA 414 e IRGA 417 apresentaram melhor desempenho. Em Cachoeira do Sul (RS) foram os genótipos BR IRGA 409, BR IRGA 414 e EL PASO 144 que se destacaram. Oliveira et al. (1999) observaram que os genótipos IRGA 318, IRGA 417, EL PASO 144, IRGA 284 e IRGA 369 destacaram-se quanto ao vigor inicial devido a maior velocidade de emissão do epicótilo em relação aos demais genótipos em Santa Vitória do Palmar (RS), mas esses apresentaram diferenças de comportamento em Cachoeirinha, evidenciando a interação genótipo $\mathrm{x}$ ambiente.

Observados em conjunto, esses dados parecem evidenciar, que o vigor inicial de plântulas no sistema pré-germinado está relacionado tanto ao genótipo quanto a fatores ambientais. Dentre os aspectos relacionados ao ambiente, pode-se destacar a grande importância da temperatura da água de irrigação no comportamento e no crescimento inicial das plântulas de arroz. Comparando genótipos de arroz, Cruz \& Milach (1999) observaram que houve variabilidade em relação à tolerância ao frio na germinação, sendo que alguns genótipos apresentaram bom nível de tolerância. Entre os genótipos testados e que pertencem a subespécie Indica, os 
genótipos mais tolerantes foram IRGA 416 e IR 8. Cruz \& Milach (2000) salientam ainda que somente a partir da caracterização precisa dos genótipos será possível obter avanços no melhoramento de arroz para tolerância ao frio no sul do Brasil. Mackill \& Lei (1997) afirmam que temperaturas baixas são o principal estresse ambiental para o cultivo de arroz nos EUA quando este é semeado cedo, mesmo que essa semeadura aconteça dentro da época normalmente recomendada. Pode-se dizer que a habilidade de germinar e sobreviver sob águas frias é um pré-requisito importante para o sucesso da cultura de arroz, principalmente no litoral sul do RS onde temperaturas de $10^{\circ} \mathrm{C}$ são comuns nos meses de setembro e outubro (Cruz \& Milach, 1999).

Sthapit \& Witcombe (1998) afirmam que as características fisiológicas como produção de clorofila, vigor da plúmula e taxa de germinação no frio são controladas geneticamente e devem ser exploradas no melhoramento de arroz irrigado uma vez que são altamente herdáveis, facilmente medidas em laboratório e se correlacionam com a performance de campo.

Tendo em vista essas considerações, o presente trabalho tem como objetivos comparar o desenvolvimento inicial de plântulas de arroz de genótipos utilizados no RS (BR IRGA 409, BR IRGA 410, IRGA 416 e IRGA 417) sob diferentes temperaturas $\left(20,25\right.$ e $\left.30^{\circ} \mathrm{C}\right)$ e avaliar o crescimento inicial das plântulas em condições de aerobiose e anaerobiose.

\section{MATERIAL E MÉTODOS}

O experimento foi realizado no Laboratório de Análise de Sementes na Universidade Federal de Pelotas. Os genótipos testados foram o BR IRGA 409, o BR IRGA 410, o IRGA 416 e o IRGA 417, pertencentes à classe de sementes básicas, tendo sido produzidas, colhidas e beneficiadas na Estação Experimental do IRGA, em Cachoeirinha, RS na safra 1997/98.

$\mathrm{Na}$ avaliação do crescimento de plântulas, foram utilizadas 20 sementes distribuídas em rolos de papel, conforme metodologia descrita por Vieira \& Carvalho (1994), com algumas adaptações, como descrito a seguir: Nos tratamentos de anaerobiose as sementes foram distribuídas em rolos de papel e esses colocados dentro de recipientes plásticos, com água destilada suficiente para cobri-los por 24 horas. Após foram drenados e mantidos em ambiente aeróbio por 24 horas, depois desse período foram novamente submersos. Esse procedimento foi realizado para os quatro genótipos. A água de embebição e de submersão foi mantida nas temperaturas controladas de 20,25 e $30^{\circ} \mathrm{C}$ até o momento da avaliação. Na condição aeróbica, as sementes foram distribuídas em rolos seguindo a mesma metodologia, porém o papel foi embebido com 2,5 vezes o seu peso com água destilada e submetidos às mesmas temperaturas. A avaliação das plântulas foi realizada aos 7 dias após a implantação do teste, com base no comprimento total da plântula, do sistema radicular e da parte aérea. $\mathrm{Na}$ temperatura de $20^{\circ} \mathrm{C}$ em anaerobiose, muitas plântulas não emitiram radícula. O cálculo foi realizado somando-se os comprimentos das radículas extrusadas e divindo-se o resultado pelo número total de plântulas germinadas.

O delineamento experimental utilizado foi inteiramente casualizado disposto em esquema fatorial, com três repetições. O fator presença de oxigênio (A) consistiu de dois níveis, aerobiose e anaerobiose. O segundo fator (B) foi formado por genótipos em quatro níveis, BR IRGA 409, BR IRGA 410, IRGA 416 e IRGA 417. O fator temperatura (C) foi composto por três níveis, 20,25 e $30^{\circ} \mathrm{C}$. As combinações entre os níveis dos fatores formaram os tratamentos do experimento, em número de vinte e quatro. Os dados foram submetidos à análise de variância com comparação de médias pelo teste de Tukey a 5\% de significância, utilizando o programa SANEST (Zonta et al. 1984).

\section{RESULTADOS E DISCUSSÃO}

A temperatura de $20^{\circ} \mathrm{C}$, que representa o limite inferior da temperatura ótima para a germinação das sementes de arroz, e que é comum no estado do Rio Grande do Sul nos meses de setembro e outubro, quando se inicia o período de semeadura do arroz, diminuiu o crescimento das plântulas, tanto em aerobiose como em anaerobiose, como pode ser observado nas Tabelas 1, 2, 3, 4 e 5 .

A Tabela 1 mostra o impacto da aeração sobre o desenvolvimento das plântulas de arroz nos genótipos estudados.

TABELA 1. Comparação do comprimento médio total das plântulas de arroz $(\mathrm{cm})$, desenvolvidas em aerobiose e em anaerobiose nas temperaturas de 20,25 e $30^{\circ} \mathrm{C}$.

\begin{tabular}{ccc}
\hline Genótipos & $\mathrm{COM} \mathrm{O}_{2}$ & $\mathrm{SEM} \mathrm{O}_{2}$ \\
BR IRGA 417 & $16,81 \mathrm{aA}$ & $4,31 \mathrm{aB}^{*}$ \\
BR IRGA 410 & $16,09 \mathrm{ab} \mathrm{A}$ & $4,15 \mathrm{ab} \mathrm{B}$ \\
BR IRGA 409 & $15,81 \mathrm{~b} \mathrm{~A}$ & $4,04 \mathrm{ab} \mathrm{B}$ \\
BR IRGA 416 & $15,36 \mathrm{~b} \mathrm{~A}$ & $3,94 \mathrm{~b} \mathrm{~B}$ \\
CV $(\%)$ & 7,332 & 8,892 \\
\hline
\end{tabular}

* Médias seguidas de letras iguais minúsculas na coluna e maiúsculas na linha, não diferem entre si a 5\% de probabilidade pelo Teste de Tukey. 
Observa-se que independente do genótipo, a deficiência de oxigênio diminui o crescimento total das plântulas e pode-se observar nas Tabelas 2, 3, 4 e 5 que o sistema radicular apresentou maior redução no crescimento do que a parte aérea das plântulas. No entanto, algumas particularidades podem ser observadas nos genótipos avaliados.

Observa-se que as plântulas de BR IRGA 409 (Tabela 2) apresentaram o crescimento da parte aérea diminuído em anaerobiose nas temperaturas de 25 e $30^{\circ} \mathrm{C}$, mas na temperatura de $20^{\circ} \mathrm{C}$ não foi observada diferença significativa, indicando que nessa temperatura, o efeito da deficiência de oxigênio não foi o fator impeditivo do crescimento da parte aérea dessas plântulas. A temperatura que mais favoreceu o crescimento do sistema radicular para plântulas de $\mathrm{BR}$ IRGA 409 em aerobiose foi a de $25^{\circ} \mathrm{C}$, enquanto que em anaerobiose, foi a de $30^{\circ} \mathrm{C}$.

A Tabela 3 apresenta os dados de crescimento de plântulas do genótipo de BR IRGA 410. A condição de anaerobiose foi limitante ao crescimento da parte aérea das plântulas nas temperaturas de 25 e $30^{\circ} \mathrm{C}$, mas não na temperatura de $20^{\circ} \mathrm{C}$. Para a condição de anaerobiose, o maior crescimento da parte aérea das plântulas ocorreu em $25^{\circ} \mathrm{C}$ e não houve diferença estatística entre as temperaturas de 20 e $30^{\circ} \mathrm{C}$. O maior crescimento do sistema radicular para esse genótipo foi no tratamento de $25^{\circ} \mathrm{C}$ aeróbico e o menor, em $20^{\circ} \mathrm{C}$ anaeróbico. Pode-se observar que o crescimento do sistema radicular desse genótipo foi o mais sensível ao tratamento de $20^{\circ} \mathrm{C}$ anaeróbico, pois apresentou diferença estatística quando comparado com as temperaturas de 25 e $30^{\circ} \mathrm{C}$ em anaerobiose.

$\mathrm{Na}$ temperatura de $20^{\circ} \mathrm{C}$, as plântulas que se originaram de sementes de IRGA 416 apresentaram um maior crescimento da parte aérea em anaerobiose do que em aerobiose, ao contrário do observado nas temperaturas de $25 \mathrm{e}$ $30^{\circ} \mathrm{C}$, onde o crescimento da parte aérea foi maior em aerobiose (Tabela 4). Em anaerobiose, não foram observadas diferenças entre o comprimento da parte aérea das plântulas nas temperaturas de 20 e $30^{\circ} \mathrm{C}$, sendo o maior cresci-
TABELA 2. Crescimento de plântulas (cm) do genótipo BR IRGA 409, nos tratamentos de temperatura e condição de aerobiose e anaerobiose.

\begin{tabular}{|c|c|c|c|c|}
\hline \multirow{2}{*}{ Parte da plântula } & \multirow{2}{*}{ Oxigênio } & \multicolumn{3}{|c|}{ Temperatura } \\
\hline & & $20^{\circ} \mathrm{C}$ & $25^{\circ} \mathrm{C}$ & $30^{\circ} \mathrm{C}$ \\
\hline \multirow{2}{*}{ Parte aérea } & Com & $1,31 \mathrm{a} \mathrm{B}$ & $6,10 \mathrm{aA}$ & $6,75 \mathrm{aA} *$ \\
\hline & Sem & $1,91 \mathrm{a} \mathrm{B}$ & $3,90 \mathrm{~b} \mathrm{~A}$ & $3,25 \mathrm{~b} \mathrm{~A}$ \\
\hline \multirow{2}{*}{ Sistema radicular } & Com & $6,30 \mathrm{aC}$ & $15,49 \mathrm{aA}$ & $11,50 \mathrm{aB}$ \\
\hline & Sem & 0,07 b B & 1,20 b AB & $1,80 \mathrm{~b} \mathrm{~A}$ \\
\hline \multirow{2}{*}{ Comprimento total } & Com & $7,61 \mathrm{a} \mathrm{C}$ & $21,58 \mathrm{aA}$ & $18,25 \mathrm{aB}$ \\
\hline & Sem & 1,97 b B & $5,10 \mathrm{~b} \mathrm{~A}$ & $5,05 \mathrm{~b} \mathrm{~A}$ \\
\hline
\end{tabular}

TABELA 3. Crescimento de plântulas (cm) do genótipo BR IRGA 410, nos tratamentos de temperatura e condição de aerobiose e anaerobiose.

\begin{tabular}{|c|c|c|c|c|}
\hline \multirow{2}{*}{ Parte da plântula } & \multirow{2}{*}{ Oxigênio } & \multicolumn{3}{|c|}{ Temperatura } \\
\hline & & $20^{\circ} \mathrm{C}$ & $25^{\circ} \mathrm{C}$ & $30^{\circ} \mathrm{C}$ \\
\hline \multirow{2}{*}{ Parte aérea } & Com & $1,62 \mathrm{aB}$ & 5,88 a A & $6,51 \mathrm{aA}$ \\
\hline & Sem & 2,22 a B & 3,90 b A & $2,68 \mathrm{~b} \mathrm{~B}$ \\
\hline \multirow{2}{*}{ Sistema radicular } & Com & $7,55 \mathrm{aC}$ & 16,43 a A & $10,27 \mathrm{aB}$ \\
\hline & Sem & 0,22 b B & 1,37 b A & 2,06 b A \\
\hline \multirow{2}{*}{ Comprimento total } & & 9,17 & 22,31 a A & 16,79 b A \\
\hline & Sem & 2,44 & $5,27 \mathrm{Ab}$ & 4,74 b B \\
\hline
\end{tabular}

* Médias seguidas de letras iguais minúsculas na coluna e maiúsculas na linha não diferem entre si ao nível de 5\% de probabilidade pelo Teste de Tukey.

TABELA 4. Crescimento de plântulas (cm) do genótipo IRGA 416, nos tratamentos de temperatura e condição de aerobiose e anaerobiose.

\begin{tabular}{|c|c|c|c|c|}
\hline \multirow{2}{*}{ Parte da plântula } & \multirow{2}{*}{ Oxigênio } & \multicolumn{3}{|c|}{ Temperatura } \\
\hline & & $20^{\circ} \mathrm{C}$ & $25^{\circ} \mathrm{C}$ & $30^{\circ} \mathrm{C}$ \\
\hline \multirow{2}{*}{ Parte aérea } & Com & 1,31 b B & $6,13 \mathrm{aA}$ & 6,63 a A \\
\hline & Sem & $2,28 \mathrm{aB}$ & 4,14 b A & 2,78 b B \\
\hline \multirow{2}{*}{ Sistema radicular } & Com & $5,80 \mathrm{aC}$ & $14,50 \mathrm{a} \mathrm{A}$ & 11,73 a B \\
\hline & Sem & 0,16 b A & 0,98 b A & 1,49 b A \\
\hline \multirow{2}{*}{ Comprimento total } & Com & 7,11 & $20,63 \mathrm{a} A$ & 18,36 b A \\
\hline & Sem & 2,44 & $5,12 \mathrm{a} B$ & 4,27 b B \\
\hline
\end{tabular}

* Médias seguidas de letras iguais minúsculas na coluna e maiúsculas na linha não diferem entre si a $5 \%$ de probabilidade pelo Teste de Tukey. 
mento na temperatura de $25^{\circ} \mathrm{C}$. O crescimento do sistema radicular das plântulas do genótipo IRGA 416 não diferiu entre temperaturas na condição de anaerobiose. Em aerobiose, o maior crescimento ocorreu na temperatura de $25^{\circ} \mathrm{C}$ (Tabela 4).

As plântulas de BR IRGA 417, nas temperaturas de 25 e $30^{\circ} \mathrm{C}$ apresentaram maior crescimento da parte aérea em aerobiose do que em anaerobiose (Tabela 5), mas na temperatura de $20^{\circ} \mathrm{C}$, o maior crescimento da parte aérea foi em anaerobiose, como também foi observado no genótipo IRGA 416 , o que pode indicar que a deficiência de oxigênio estimula o crescimento da parte aérea das plântulas para que essas busquem o oxigênio mais rapidamente na temperatura de $20^{\circ} \mathrm{C}$. Essas observações permitem afirmar que os genótipos BR IRGA 410, IRGA 416 e IRGA 417 adaptaram-se melhor à condição de anaerobiose em temperaturas baixas $\left(20^{\circ} \mathrm{C}\right)$ do que o genótipo BR IRGA 409.

O crescimento do sistema radicular das plântulas de IRGA 417 sofreu interferência da temperatura na aerobiose, mas, na anaerobiose não há diferença estatística no tamanho desse, entre as temperaturas testadas (Tabela 5). Pode-se observar que, em aerobiose, a temperatura que proporcionou maior crescimento da parte aérea das plântulas de IRGA 417 foi $30^{\circ} \mathrm{C}$, e em anaerobiose foi $25^{\circ} \mathrm{C}$.

Os resultados apresentados nas Tabelas 1, 2, 3, 4 e 5 confirmam as observações feitas por Cruz \& Milach (1999), Ishiy et al. (1999), Rosso et al. (1999), Sthapit \& Witcombe (1998) e Mackill \& Lei (1997) de que fatores ambientais como temperatura e disponibilidade de oxigênio influenciam o comportamento dos genótipos, quanto ao crescimento das plântulas.

TABELA 5. Crescimento de plântulas (cm) do genótipo IRGA 417, nos tratamentos de temperatura e condição de aerobiose e anaerobiose.

\begin{tabular}{|c|c|c|c|c|}
\hline \multirow{2}{*}{ Parte da plântula } & \multirow{2}{*}{ Oxigênio } & \multicolumn{3}{|c|}{ Temperatura } \\
\hline & & $20^{\circ} \mathrm{C}$ & $25^{\circ} \mathrm{C}$ & $30^{\circ} \mathrm{C}$ \\
\hline \multirow{2}{*}{ Parte aérea } & Com & 1,43 b C & 6,63 a B & $7,37 \mathrm{aA}$ \\
\hline & Sem & $2,61 \mathrm{aC}$ & 3,86 b A & 3,21 b B \\
\hline \multirow{2}{*}{ Sistema radicular } & Com & $6,86 \mathrm{aC}$ & 15,44 a A & $12,70 \mathrm{aB}$ \\
\hline & Sem & 0,17 b A & 1,56 b A & 1,53 b A \\
\hline \multirow{2}{*}{ Comprimento total } & Com & 8,29 & 22,07 a A & 20,07 b A \\
\hline & Sem & 2,77 & 5,42 a B & 4,75 b B \\
\hline
\end{tabular}

* Médias seguidas de letras iguais minúsculas na coluna e maiúsculas na linha não diferem entre si a 5\% de probabilidade pelo Teste de Tukey.
Yamauchi \& Winn (1996) afirmam que a elongação rápida do coleóptilo em solo anaeróbico pode encurtar o tempo para as plântulas alcançarem o $\mathrm{O}_{2}$ na superfície do solo, permitindo, dessa forma, um bom desenvolvimento de folhas e raízes. Quando observado o crescimento da parte aérea das plântulas dos genótipos IRGA 416 e IRGA 417 nos diferentes tratamentos, o comportamento dessas plântulas foi muito semelhante. No tratamento com temperatura de $20^{\circ} \mathrm{C}$ em anaerobiose, as plântulas dos dois genótipos apresentaram crescimento superior ao de aerobiose, enquanto que as plântulas dos genótipos BR IRGA 409 e BR IRGA 410 não diferiram estatisticamente nessa temperatura nas condições de aerobiose e anaerobiose, evidenciando a interação genótipo x ambiente. Isso concorda com Dilday et al. (1990), que observaram diferenças significativas entre genótipos quanto ao crescimento da parte aérea de plântulas.

Nas Tabelas 2, 3, 4 e 5 pode-se observar que em anaerobiose, o crescimento da parte aérea é maior na temperatura de $25^{\circ} \mathrm{C}$ do que na temperatura de $30^{\circ} \mathrm{C}$, discordando de Chapman \& Peterson (1962) que afirmam que a emergência da parte aérea a partir de solo alagado é mais rápida com temperatura de $30^{\circ} \mathrm{C}$, possivelmente porque os genótipos utilizados estão adaptadas para temperaturas mais amenas.

Mackill \& Lei (1997) constataram que os genótipos pertencentes à subespécie Índica são menos tolerantes ao estresse por frio no início do desenvolvimento das plântulas do que os genótipos pertencentes à subespécie Japônica Tropical. Porém, observaram diferenças entre os genótipos índicas quanto à adaptação a temperaturas mais baixas e dividiram em 2 grupos os genótipos Índicos que estavam em estudo, entre melhor e pior adaptação ao frio. Pode-se também identificar os genótipos BR IRGA 410, IRGA 416 e IRGA 417 como tolerantes à condição ambiental de $20^{\circ} \mathrm{C}$ em anaerobiose (Tabelas 3, 4 e 5), pois nessa temperatura cresceram mais na condição de anaerobiose do que em aerobiose. Essa característica pode ser de grande interesse para semeaduras no sistema pré-germinado nas regiões onde acontecem temperaturas baixas nos meses de semeadura do arroz.

Os genótipos BR IRGA 409 e BR IRGA 410 não diferiram estatisticamente quanto ao crescimento da parte aérea na temperatura de $20^{\circ} \mathrm{C}$ em aerobiose e anaerobiose. Em condição de aerobiose as plântulas dos genótipos BR IRGA 409 e BR IRGA 410 apresentaram comportamento muito se- 
melhante na temperatura de $20^{\circ} \mathrm{C}$. Ambos tiveram a mesma intensidade de crescimento nos ambientes aeróbico e anaeróbico, possivelmente devido ao alto grau de similaridade que existe entre esses genótipos, como foi constatado por Bonow (1999).

Porém, na aerobiose, nenhum genótipo se destacou no aspecto de crescimento da parte aérea na temperatura de $20^{\circ} \mathrm{C}$. Avaliando o crescimento da parte aérea de plântulas de vários genótipos, Redoña \& Mackill (1996) observaram que a variação da temperatura de crescimento de plântulas de $18^{\circ} \mathrm{C}$ para $25^{\circ} \mathrm{C}$ aumentou o crescimento da parte aérea das plântulas de todos os genótipos avaliados. O comportamento dos genótipos no presente experimento ocorreu de forma semelhante, pois as plântulas aumentaram seu crescimento quando a temperatura variou de 20 para $25^{\circ} \mathrm{C}$ tanto em aerobiose como em anaerobiose (Tabelas 1, 2, 3, 4 e 5).

Bewley \& Black (1994) afirmam que sementes de arroz e de outras espécies aquáticas germinam e crescem sob água e que mostram algumas adaptações interessantes para essa condição de reduzida disponibilidade de oxigênio. Essas espécies germinam em ambientes totalmente livres de oxigênio, no entanto, apenas o coleóptilo elonga e o crescimento radicular é inibido. No sistema de semeadura pré-germinado, o desenvolvimento do sistema radicular tem papel muito importante para que a lavoura se estabeleça com uma distribuição homogênea das plântulas. Os genótipos que têm capacidade de enraizamento em condições de anaerobiose e/ou em temperaturas baixas, podem ter melhor desempenho no sistema de semeadura pré-germinada no estado do Rio Grande do Sul.

Contrariando as afirmações de Chapman \& Peterson (1962), o crescimento do sistema radicular foi menor com temperatura baixa, de $20^{\circ} \mathrm{C}$. As Tabelas 2, 3, 4 e 5 mostram o efeito marcante do ambiente sobre o crescimento do sistema radicular dos genótipos testados, onde a temperatura de $20^{\circ} \mathrm{C}$ inibiu quase totalmente o desenvolvimento desses em anaerobiose.

\section{CONCLUSÕES}

A) O genótipo BR IRGA 409 mostrou-se menos adaptado à semeadura em anaerobiose, quando em temperatura de $20^{\circ} \mathrm{C}$.

B) Em anaerobiose, os genótipos apresentam crescimento radicular maior em temperaturas mais altas.

\section{REFERÊNCIAS}

BEWLEY, J.D.; BLACK, M. Seeds - physiology of development and germination. 2ed. New York: Plenum Press, 1994. 445 p.

BONOW, S. Caracterização e análise de pureza varietal em genótipos de Oryza sativa L. através de isoenzimas. 1999. 44 f. Dissertação (Mestrado) - Universidade Federal de Pelotas, Pelotas.

CHAPMAN, A.L.; PETERSON, M.L. The seedling establishment of rice under water in relation to temperature and dissolved oxygen. Crop Science, Madison, v.2, p.391-395, 1962.

CRUZ, R.P., da; MILACH, S.C.K. Avaliação de genótipos de arroz quanto à tolerância ao frio na germinação. In: REUNIÃO DA CULTURA DO ARROZ IRRIGADO, 23., 1999, Pelotas. Anais... Pelotas: UFPel: EMBRAPA-CPACT, 1999. p.42-43.

CRUZ, R.P., da; MILACH, S.C.K. Melhoramento genético para tolerância ao frio em arroz irrigado. Ciência Rural, Santa Maria, v. 30, n.5, p.909-917, 2000.

DILDAY, R.H.; MGONJA, M.A.; AMONSILPA, S.A.; COLLINS, F.C.; WELLS, B.R. Plant height vs. mesocotyl and coleoptile elongation in rice: linkage or pleitropism? Crop Science, Madison, v. 30, p.815-818, 1990.

IRGA. Instituto Riograndense do Arroz. Lavoura Arrozeira, Porto Alegre, v.51, p.14-15, 2000.

ISHIY, T.; SCHIOCCHET, M.A.; NOLDIN, J.A. Comportamento de linhagens e cultivares de arroz submetidas à condições de inundação permanente. In: REUNIÃO DA CULTURA DO ARROZ IRRIGADO, 23., 1999, Pelotas. Anais... Pelotas: UFPel: EMBRAPA-CPACT, 1999. p.117-119.

MACKILL, D.J.; LEI, X. Genetic variation for traits related to temperature adaptation of rice cultivars. Crop Science, Madison, v.37, p.1340-1346. 1997.

OLIVEIRA J.C.S. de; RAMIREZ, H.V.; MENEZES, V.G.; ROSSO, A.F. de; BAUER, C.A.; NEVES, G. Avaliação de genótipos de arroz irrigado sob sistema pré-germinado. In: REUNIÃO DA CULTURA DO ARROZ IRRIGADO, 23., 1999, Pelotas. Anais... Pelotas: UFPel: EMBRAPA-CPACT, 1999. p.59-60.

PETRINI, J.A.; TAVARES, W.R.F.;FRANCO, D.F.; Comportamento de oito cultivares de arroz irrigado em diferentes épocas de semeadura no sistema pré-germinado. In: REUNIÃO DA CULTURA DO ARROZ IRRIGADO, 22., 1997, Balneário Camburiú. Anais... Itajaí: EPAGRI, 1997. p.197-199.

PONNAMPERUMA, F.N. The chemistry of submerged soils. Advances in Agronomy, New York, v.24, p.29-96, 1972.

REDOÑA, E.D.; MACKILL, D.J. genetic variation for seedling vigor traits in rice. Crop Science, Madison, v.36, p. 285-290, 1996.

ROSSO, A.F. de; LOPES, S.I.G.; CARMONA, P.S.; BARROS, J. de A.I. de. Competição de genótipos de arroz irrigado em sistema de cultivo pré-germinado em Cachoeirinha e Cachoeira do Sul/RS, safra 1998/99. In: REUNIÃO DA CULTURA DO ARROZ IRRIGADO, 23., 1999, Pelotas. Anais... Pelotas: UFPel: EMBRAPA-CPACT, 1999. p.100-101. 
STHAPIT, B.R.; WITCOMBE, J.R. Inheritance of tolerance to chilling stress in rice during germination and plumule greening. Crop Science, Madison, v.38, p.660-665, 1998.

VIEIRA, R.D.; CARVALHO, N.M. de. Testes de vigor em sementes. Jaboticabal: FUNEP, 1994. 164p.

YAMAUCHI, M. AGUILAR, A.M.; VAUGHAN, D.A.; SESHU, D.V. Rice (Oryza sativa L.) germoplasm suitable for direct sowing under flooded soil surface. Euphytica, Dordrecht, v.67, p.177-184, 1993.

YAMAUCHI, M.; WINN, T. Rice seed vigor and seedling establishment in anaerobic soil. Crop Science, Madison, v.36, p.680686, 1996.

ZONTA, E.P.; MACHADO, A.A. Sistema de análise estatística para microcomputadores - SANEST. Pelotas, 1984.

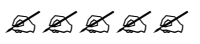

